\title{
COOPERAÇÃO JURÍDICA INTERNACIONAL: DO AUXÍLIO DIRETO NA PERSECUÇÃO DE CRIMES DE LAVAGEM DE CAPITAIS
}

Jordan Tomazelli Lemos*

Margareth Vetis Zaganelli**

SUMÁRIO: Introdução; 2 Lavagem de capitais no plano transnacional; 3 Base legal da cooperação internacional; 4 Auxílio direto; 5 Auxílio internacional na decretação de medidas cautelares em crimes envolvendo a lavagem de capitais; 6 Procedimento para requisição de cooperação jurídica internacional; 6.1 Solicitação de dados bancários para apurar fatos envolvendo lavagem de capitais; 7 Considerações finais; Referências

RESUMO: O presente artigo tem por intencionalidade analisar os mecanismos jurídicos internacionais que objetivam a eficácia da persecução penal em crimes de lavagem ou ocultação de bens, direitos ou valores, condutas delituosas tipificadas na lei $\mathrm{n}^{0} 9.613 / 1998$. Por meio de metodologia qualitativa, utilizando pesquisa bibliográfica, aborda inicialmente as consequências da lavagem de capitais, de caráter transnacional. A seguir, descrevem-se os mecanismos e a base legal da cooperação internacional que visam interromper o exaurimento das fases que envolvem a ocultação e a reinserção de produto de crime no mercado financeiro. $\mathrm{O}$ trabalho ressalta a importância do auxílio direto na eficácia das medidas assecuratórias, em que os órgãos competentes, por meio da Autoridade Central, colaboram a fim de garantir os efeitos genéricos da condenação.

PALAVRAS-CHAVE: Lavagem de capitais; Cooperação jurídica internacional; Medidas cautelares reais; Auxílio direto; Sigilo bancário.

\section{INTERNATIONAL LEGAL COOPERATION: MUTUAL LEGAL ASSISTANCE IN PURSUIT OF CAPITAL LAUNDERING CRIMES}

ABSTRACT: This article is to analyse the international legal mechanisms intentionality that aim the effectiveness of criminal prosecution on crimes of washing or concealment of property, rights or values, illegal conducts typified in law $n^{\circ} 9,613 / 1998$. By using qualitative methodology, using bibliographical research, discusses the consequences initially capital laundering, transnational character. The following des-

\footnotetext{
Advogado. Mestrando em Direito Processual pela Universidade Federal do Espírito Santo (UFES), Brasil. E-mail: jordan_tl@hotmail.com

** Doutora em Direito (UFMG). Estágio Pós-doutoral na Università degli Studi di Milano-Bicocca (UNIMIB) e na Alma Mater Studiorum Università di Bologna(UNIBO). Docente Titular da Universidade Federal do Espírito Santo (UFES), Brasil.
} 
cribes the mechanisms and the legal basis of international cooperation aimed at interrupting the fatigue of the phases involving the concealment and reinsertion of product of crime in the financial market. The work highlights the importance of Direct Aid on the efficiency of advisory measures, where the competent organs, through the Central Authority, cooperate in order to ensure that the generic effects of the conviction.

KEY WORDS: Money Laundering; International Legal Cooperation; Real Precautionary Measures; Mutual Legal Assistance; Bank Secrecy.

\section{COOPERACIÓN JURÍDICA INTERNACIONAL: DE LA AYUDA DIRECTA EN LA PERSECUCIÓN DE CRÉDITOS DE LAVADO DE CAPITALES}

RESUMEN: El presente artículo tiene por intencionalidad analizar los mecanismos jurídicos internacionales que objetivan la eficacia de la persecución penal en crímenes de lavado u ocultación de bienes, derechos o valores, conductas delictivas tipificadas en la Ley $n^{0} 9.613$ / 1998. Por medio de metodología cualitativa, utilizando investigación bibliográfica, aborda inicialmente las consecuencias del lavado de capitales, de carácter transnacional. A continuación, describe los mecanismos y la base legal de la cooperación internacional que pretende interrumpir el agotamiento de las fases implicando la ocultación y la reinserción de producto de crimen en el mercado financiero. El trabajo resalta la importancia del Auxilio Directo en la eficacia de las medidas firmes, donde los órganos competentes, por medio de la Autoridad Central, colaboran a fin de garantizar los efectos genéricos de la condena.

PALABRAS CLAVE: Lavado de Capitales; Cooperación Jurídica Internacional; Medidas Cautelares Reales; Ayuda Directa; El Secreto Bancario.

\section{INTRODUÇÃO}

Nas últimas décadas, o alto índice de delitos cometidos no território brasileiro tem ocasionado intensa produção legiferante do Congresso Nacional. Consequência deste ativismo são as inúmeras leis penais e processuais penais esparsas que visam à persecução penal e finalmente a punição daqueles que insistem em ultrapassar os limites do convívio social.

Porém, as condutas ilícitas não se limitam ao território nacional, havendo muitos crimes que rompem as fronteiras do Brasil, ou seja, fração envolvendo a 
preparação, execução ou resultado do delito ocorre no estrangeiro. É esta a noção de crime transnacional aposta na Convenção de Palermo, de 2000, em que ou o fato delituoso ou os agentes infratores adotam plúrimas nações. ${ }^{03}$

Percebeu o legislador que tal internacionalização dificulta a atuação da polícia judiciária e também do próprio Poder Judiciário, haja vista demandar mais recursos e cooperação de entes internacionais, já que a atuação unilateral de uma nação em território estrangeiro é séria afronta à soberania de um Estado. ${ }^{04}$

Foi também pensando nestes entraves que foram editadas leis que punem mais severamente os crimes que extrapolam as barreiras geográficas, como, dentre outras, as previsões do art. $2^{\mathrm{o}}, \S^{\mathrm{o}}$, $\mathrm{V}$, da lei $\mathrm{n}^{\mathrm{o}} 12.850$, de 2 de agosto de $2013^{05}$ e do art. 40, I, da lei $\mathrm{n}^{\mathrm{o}} 11.343$, de 23 de agosto de $2006^{06}$.

É nesse contexto que o presente estudo, por meio de metodologia qualitativa, com base em pesquisa bibliográfica, expõe a importância da cooperação jurídica internacional em matéria envolvendo a persecução penal. Isto porque o Estado brasileiro não tem mecanismos - nem autorização - suficientes para investigar e instruir adequadamente uma ação penal envolvendo crimes de caráter transnacional. Necessário, portanto, um diálogo com as demais soberanias envolvidas, para que seja possível a obtenção de dados relevantes para a elucidação dos fatos criminosos, dados estes cuja jurisdição brasileira não é competente para se imiscuir.

Assim, o trabalho focará na cooperação jurídica internacional visando o combate à lavagem de capitais, crime que ameaça o Estado democrático de Direito, a economia e a segurança da comunidade como um todo ${ }^{07}$, haja vista que os crimes antecedentes são passíveis de maior fomento e perpetuação.

Em crimes cuja prática dos atos executórios ocorrem quase que integralmente no exterior, a cooperação dos demais países é a única forma para que sejam colhidos elementos mínimos de autoria e prova de materialidade, não havendo sem

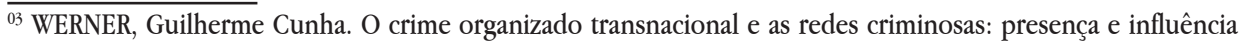
nas relações internacionais contemporâneas. Tese (Doutorado). São Paulo. Universidade de São Paulo. Departamento de Ciências Políticas, 2009, p. 50. Disponível em: < http://www.tribunapr.com.br/noticias/o-crime-organizado-na-visao-da-convencao-de-palermo/> . Acesso em: novembro de 2017.

${ }^{04}$ BOBBIO, Norberto et al. Dicionário de política. 6. ed. Trad. Carmem Varrialle et al. Brasília: Ed. da UnB, 1994, p. 1.187.

${ }^{05}$ A pena é aumentada de $1 / 6$ (um sexto) a 2/3 (dois terços) se as circunstâncias do fato evidenciarem a transnacionalidade da organização.

${ }^{06}$ As penas previstas nos arts. 33 a 37 desta Lei são aumentadas de um sexto a dois terços, se a natureza, a procedência da substância ou do produto apreendido e as circunstâncias do fato evidenciarem a transnacionalidade do delito.

${ }^{07}$ MEDEIROS, Ana Rosa de Brito. The International Cooperation in Criminal Matters and The International Assets Recovery: Progress and Challenges to Brazil in order to Fight Against the Money Laundering. 2012. 100 f. Dissertação (Mestrado em ciências jurídicas) - Universidade Federal da Paraíba, João Pessoa, 2012, p. 14.
} 
o referido repasse de informações sequer a presença de justa causa, condição da ação elementar para o recebimento de eventual ação penal ${ }^{08}$.

Diante de tal problemática, abordar-se-á preliminarmente a lavagem de capitais no plano transnacional, para, em seguida, ser abordada a influência das relações jurídicas internacionais nos mecanismos de cooperação jurídica.

Com tais premissas, será então estudado o Auxílio Direto nas investigações e combate aos delitos envolvendo a lavagem de capitais, sendo apontadas medidas jurídico-diplomáticas em prol do combate ao crime organizado.

\section{LAVAGEM DE CAPITAIS NO PLANO TRANSNACIONAL}

Os processos que envolvem a prática de lavagem de capitais, com suas respectivas fases de ocultação e reinserção do valor no mercado, já são complexos para o seu rastreamento em âmbito nacional. ${ }^{09}$ Imaginando que uma organização criminosa se articule o suficiente para enviar o produto de crime para outra nação, cometendo a denominada evasão de divisas, seria quase impossível um país ter, isoladamente, controle de todo o iter criminis perpetrado pelo criminoso.

Para melhor análise do objeto de estudo, é necessária uma síntese das fases que envolvem a lavagem de dinheiro. Neste sentido, é do Conselho de Controle de Atividades Financeira (COAF), órgão vinculado ao Ministério da Fazenda, a lição acerca das etapas envolvendo o delito.

1. Colocação - a primeira etapa do processo é a colocação do dinheiro no sistema econômico. Objetivando ocultar sua origem, o criminoso procura movimentar o dinheiro em países com regras mais permissivas e naqueles que possuem um sistema financeiro liberal. A colocação se efetua por meio de depósitos, compra de instrumentos negociáveis ou compra de bens. Para dificultar a identificação da procedência do dinheiro, os criminosos aplicam técnicas sofisticadas e cada vez mais dinâmicas, tais como o fracionamento dos valores que transitam pelo sistema financeiro e a utilização de estabelecimentos comerciais que usualmente trabalham com dinheiro em espécie.

2. Ocultação - a segunda etapa do processo consiste em dificultar o rastreamento contábil dos recursos ilícitos. O objetivo é quebrar a cadeia de evidências ante a possibilidade da realização de investigações

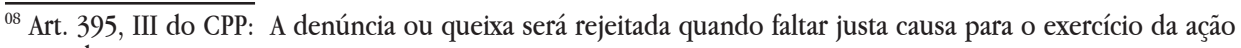
penal.

${ }^{09}$ DAMIN, Leonardo. Da importância da cooperação jurídica internacional nos crimes de lavagem de dinheiro. Disponível em:<https://leodamin.jusbrasil.com.br/artigos/433383334/da-importancia-da-cooperacao-juridica -internacional-nos-crimes-de-lavagem-de-dinheiro > . Acesso em: junho de 2017.
} 
sobre a origem do dinheiro. Os criminosos buscam movimentá-lo de forma eletrônica, transferindo os ativos para contas anônimas - preferencialmente, em países amparados por lei de sigilo bancário - ou realizando depósitos em contas abertas em nome de "laranjas" ou utilizando empresas fictícias ou de fachada.

3. Integração - nesta última etapa, os ativos são incorporados formalmente ao sistema econômico. As organizações criminosas buscam investir em empreendimentos que facilitem suas atividades - podendo tais sociedades prestarem serviços entre si. Uma vez formada a cadeia, torna-se cada vez mais fácil legitimar o dinheiro ilegal. ${ }^{10}$

Assim, verifica-se que é já na primeira etapa que, para melhor exaurimento do objetivo infracional - a depender do montante auferido -, busca o agente encaminhar o valor relativo ao produto de crime para nações estrangeiras, já que a movimentação financeira controlada pelas instituições nacionais se limitam à análise interna, sendo natural a falta de rastro acerca de movimentações futuras e externas.

Com o recente destaque da "Operação Lava Jato", que foi inaugurada em março de $2014^{11}$ e atualmente pode ser considerada a maior investigação envolvendo crimes contra a administração pública do país (tendo a empresa estatal de economia mista Petrobras como órgão alvo dos agentes criminosos que buscavam contratos superfaturados $)^{12}$, verificou-se que a corrupção é um dos crimes antecedentes mais difíceis de serem combatidos, diante do caráter sistêmico que pode adquirir nas instituições da administração pública.

Segundo ranking da Transparência Internacional, divulgado em $2016^{13}$, o Brasil ocupa a $79^{\mathrm{a}}$ posição numa lista envolvendo 176 países quando o assunto é corrupção. Numa metodologia de 0 (extremamente corrupto) a 100 (muito transparente), o índice brasileiro atingiu 40 pontos, demonstrando que os recentes escândalos que envolvem o alto escalão dos poderes Executivo e Legislativo federais não são fatos isolados, atingindo toda a sociedade.

Normalmente, os agentes criminosos se valem dos denominados paraísos fiscais para remeterem o montante, países onde há menor fiscalização de transações financeiras e há menor carga tributária incidindo sobre os ativos. ${ }^{14}$

\footnotetext{
${ }^{10}$ Conselho de Controle de Atividades Financeiras. Fases da Lavagem de Dinheiro. Disponível em: < http://www. coaf.fazenda.gov.br/inks-externos/fases-da-lavagem-de-dinheiro > . Acesso em: novembro de 2016.

${ }^{11}$ Polícia Federal. Disponível em: <http://www.pf.gov.br/imprensa/lava-jato/fases-da-operacao-lava-jato-1> . Acesso em: novembro de 2017.

${ }^{12}$ Ministério Público Federal. Caso Lava Jato. Disponível em: < http://www.mpf.mp.br/para-o-cidadao/caso-lavajato/entenda-o-caso > . Acesso em: novembro de 2017.

${ }^{13}$ Transparency International. Corruption Perceptions Index 2016. Disponível em: < https://www.transparency. org/news/feature/corruption_perceptions_index_2016>. Acesso em: julho de 2017.

${ }_{14}^{14}$ TORRES, Heleno. Direito tributário internacional: planejamento tributário e cooperação transnacionais. São Paulo: Revista dos Tribunais, 2001, p. 86.
} 
É com esta premissa que surge a maior problemática envolvendo a lavagem de capitais em âmbito internacional: além de valerem-se do lucro obtido para fomentar o crime antecedente, a reinserção com caráter lícito ocasiona o desequilíbrio econômico financeiro entre mercados idôneos e mercados que se valem de capital ilícito para superar a concorrência.

Considerando que as grandes multinacionais, presentes em Bolsas de Valores de diversos países, são responsáveis pela movimentação do capital em nível global, não haveria governo que resistisse à pressão de combate a ilícitos que afetam o mercado interno, razão pela qual resta evidente que

As autoridades internacionais já se revelaram simpatizantes com relação à criação de um sistema penal e processual penal internacional, fundamentado nas diretrizes envoltas aos direitos humanos, de maneira que, cada vez mais, se combata não apenas este, mas todos os crimes de caráter organizado e transnacional. Essa realidade já é bastante sentida através do que ele denomina de 'sistemas globais de proibição'."15

Naturalmente que o dano gerado pelos denominados crimes antecedentes à lavagem de dinheiro são de extrema gravidade (disseminação de substâncias maléficas à saúde por meio do tráfico de entorpecentes, desvio de verba pública e consequente ausência de serviços essenciais à população em decorrências da corrupção etc.), porém, a reinserção de produto de crime no mercado capital é capaz de desestabilizar sistematicamente a economia de um país.

No entanto, o combate a tal mácula não é passível de exercício isolado por uma soberania, haja vista que as organizações criminosas estão envolvidas e estruturadas de tal forma que os métodos tradicionais de prevenção e coerção estão se revelando ineficazes ao combate de tais entes cuja estrutura se compara ou equivale às empresas multinacionais.

\section{BASE LEGAL DA COOPERAÇÃO JURÍDICA INTERNACIONAL}

Vivencia-se uma era em que a globalização e a troca de experiência entre as nações é essencial para o desenvolvimento de um país, especialmente por imperar

\footnotetext{
${ }^{15}$ TEÓFILO, Anna Mayra Araújo; BRAGA Rômulo Rhemo Palitot. Cooperação Penal Internacional nos crimes de Lavagem De Dinheiro. Disponível em: <www.publicadireito.com.br/artigos/?cod=571e646d4ea4d46a > . Acesso em: junho de 2017, p. 13.
} 
no mundo o sistema capitalista na economia. Eis que surgem então diversas frentes de colaboração entre aliados, instrumentos oportunos para o crescimento das virtudes e a perseguição às máculas de cada cultura.

O comprometimento do Brasil com as relações jurídicas e administrativas internacionais é regrada em âmbito constitucional e em âmbito ordinário pelo Código de Processo Civil, aplicável subsidiariamente ao Processo Penal. ${ }^{16}$

$\mathrm{Na}$ Constituição Cidadã, evidencia-se no art. $4^{\mathrm{o}}$, IX ${ }^{17}$ que a cooperação entre os povos para o progresso da humanidade figura como princípio regente das relações internacionais, que objetiva mitigar as disparidades sociais que maculam o desenvolvimento das nações. ${ }^{18}$

Naturalmente que a persecução às organizações criminosas se faz necessária para permitir que a sociedade progrida com maior facilidade, haja vista que agentes criminosos, em muitos aspectos, conseguem exercer influência política sobre a governabilidade de um país.

Já os dispositivos transcritos no Código de Processo Civil (CPC) revelam verdadeiras cláusulas gerais para o Brasil e entidades internacionais, não havendo distinção se figuram no polo ativo ou passivo da demanda.

É no código processual vigente que surge positivada a expressão "Auxílio Direto" (art. 28 do CPC). Apesar de já exercida no ordenamento pátrio por meio dos costumes estudados pelo Direito Internacional, o regramento veio delimitar e dar maior segurança jurídica ao instituto, cuja via diplomática beneficia a celeridade procedimental.

É o inciso II do art. 30 do mencionado diploma processual que traz maior relevância em matéria penal, ao prescrever que o Auxílio Direto tem por objeto a colheita de provas ${ }^{19}$. Porém, ressalva-se que tal procedimento não escaparia a um juízo de admissibilidade pelo judiciário do Estado requerente, "pela qual a autoridade brasileira previamente controla a compatibilidade entre a medida de cooperação solicitada e as causas de competência exclusiva do juiz brasileiro" ${ }^{20}$.

\footnotetext{
${ }^{16}$ Art. $3^{\circ}$ do CPP: A lei processual penal admitirá interpretação extensiva e aplicação analógica, bem como o suplemento dos princípios gerais de direito.

${ }^{17}$ A República Federativa do Brasil rege-se nas suas relações internacionais pelos seguintes princípios: [...] cooperação entre os povos para o progresso da humanidade.

${ }^{18}$ BULOS, Uadi Lammêgo. Curso de direito constitucional. 8. ed. rev. e atual. de acordo com a Emenda Constitucional n. 76/2013. São Paulo: Saraiva, 2014, p. 522.

${ }^{19}$ Art. 30, II do CPC: Além dos casos previstos em tratados de que o Brasil faz parte, o auxílio direto terá os seguintes objetos: colheita de provas, salvo se a medida for adotada em processo, em curso no estrangeiro, de competência exclusiva de autoridade judiciária brasileira.

${ }^{20}$ STRECK, Lenio Luiz. Comentários ao código de processo civil; coordenador executivo Alexandre Freire. São Paulo: Saraiva, 2016, p. 91.
} 
Não é demais ressaltar que, na colheita probatória que vier a instruir o processo penal brasileiro, também será verificado se a obtenção dos elementos observou as garantias constitucionais em favor do investigado ou acusado, sendo desentranhadas as provas que violarem a princípios fundamentais. ${ }^{21}$

Assim, no caso de cooperação ativa, apesar de ser aplicada a legislação estrangeira na obtenção da prova, caberá à Autoridade Central brasileira verificar se os pedidos a serem enviados ao exterior também possuem fundamentos aptos a conferirem licitude em território nacional. ${ }^{22}$

Neste aspecto, cumpre ao Departamento de Recuperação de Ativos e Cooperação Jurídica Internacional do Ministério da Justiça e Segurança Pública (DRCI/ MJ), como Autoridade Central brasileira, realizar a análise e a tramitação dos pedidos de assistência jurídica internacional em matéria penal ${ }^{23}$, sendo importante ferramenta para a interrupção de crimes continuados e consequente recuperação de ativos cuja origem é ilícita ${ }^{24}$.

\section{Acerca da função do DRCI/MJ}

A figura da autoridade central consiste assim numa espécie de intermediário centralizador dos pedidos, sendo o órgão responsável pelo recebimento dos pedidos ativos do Brasil, encaminhando-os aos respectivos destinatários, bem como receber os pedidos passivos do Brasil, distribuindo-os para cumprimento. ${ }^{25}$

A solicitação a tal órgão governamental no Brasil ${ }^{26}$, em sua maioria, é feita pelos entes que atuam diretamente na investigação dos delitos internacionais, quais sejam, Ministério Público Federal (MPF), Polícia Federal (PF) e Justiça Federal (JF).

Valendo-se das demandas oriundas da "Operação Lava Jato", é possível esclarecer como funciona o instrumento da cooperação internacional

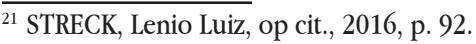

${ }^{22}$ SIQUEIRA, Marcelo Gustavo Silva. A Jurisdição e a Cooperação Internacional no Projeto de Lei do Novo Código de Processo Civil (conforme aprovado no Senado). Revista Eletrônica de Direito Processual - REDP. Volume VIII. Periódico da Pós-Graduação Stricto Sensu em Direito Processual da UERJ. Patrono: José Carlos Barbosa Moreira www.redp.com.br ISSN 1982-7636, p. 735-736.

${ }^{23}$ DITTRICH, Lalisa Froeder. Cooperação Jurídica Internacional relacionada à Operação Lava Jato. Cooperação em Pauta $-\mathrm{n}^{0}$ 14/2016. Disponível em: < http://www.justica.gov.br/sua-protecao/lavagem-de-dinheiro/institucional-2/publicacoes/cooperacao-em-pauta/cooperacao-em-pauta-n14>. Acesso em: junho de 2017.

${ }^{24}$ Segundo informação do Ministério da Justiça disponível em http://www.justica.gov.br/sua-protecao/cooperacao-internacional/cooperacao-juridica-internacional-em-materia-penal, no Brasil mais de $80 \%$ dos pedidos de cooperação internacional são ativos, significando que, além da natural preocupação com o combate a crimes transnacionais, o Estado brasileiro revela sua fragilidade em estancar as práticas delituosas.

${ }^{25}$ ANSELMO, Márcio Adriano Lavagem de dinheiro e cooperação jurídica internacional. São Paulo: Saraiva, 2013, p. 127.

${ }^{26}$ Art. 26, IV do CPC: A cooperação jurídica internacional será regida por tratado de que o Brasil faz parte e observará a existência de autoridade central para recepção e transmissão dos pedidos de cooperação.
} 
Os pedidos elaborados pelo MPF e pela PF têm por finalidade a obtenção de provas diversas; quebras de sigilo bancário; buscas e apreensões e oitivas de testemunhas; bem como medidas assecuratórias sobre bens e valores - tais como bloqueios, apreensões e sequestros - e repatriação de ativos localizados no exterior. Já os pedidos provenientes da Justiça Federal, em geral, têm como objetivos a realização de citações de réus; intimações e oitivas de testemunhas de defesa, que se encontram em território estrangeiro. Há ainda pedidos de extradição de pessoas investigadas encontradas e detidas em países estrangeiros. Tal fato demonstra a diversidade de demandas e necessidades que podem surgir no âmbito de uma mesma investigação de grande porte. ${ }^{27}$

Tal volume, que se evidenciam todos os dias perante a mídia nacional revela que, em se tratando de crimes envolvendo lavagem de capitais, os capítulos V, VI e VII da lei $\mathrm{n}^{0} 9.613$, de 1998 , que tratam de medidas a serem adotadas pelas instituições financeiras no controle da movimentação de ativos ${ }^{28}$, não são suficientes para evitar que as etapas envolvendo a reinserção de capital de origem criminosa no mercado nacional sejam cumpridas.

\section{AUXílio DIRETO}

A origem mais remota da cooperação internacional direta em matéria penal pode ser encontrada na Convenção sobre Assistência Mútua em Matéria Criminal do Conselho Europeu ${ }^{29}$, firmada em Estrasburgo em 1959, tratado de auxílio em matéria penal. Além das medidas tradicionais de cooperação internacional, como a rogatória e a extradição, contém medidas de cooperação direta, como o auxílio mútuo entre autoridades encarregadas da persecução penal e mesmo entre autoridades judiciárias. Estas medidas se diferenciam daquelas considerando que embora o objeto da diligência requerida possa ser o mesmo, dispensam o juízo de delibação e, portanto, a intermediação de outra autoridade que não as envolvidas na diligência. A expressão mutual legal assistance vem sendo utilizada na atualidade, para se referir às medidas de auxílio direto.

\footnotetext{
${ }^{27}$ GIACOMET, Isalino Antonio; SILVEIRA, Arnaldo José Alves. Desempenho da cooperação jurídica internacional nos três anos de "lava jato". Disponível em: < http://www.conjur.com.br/2017-mar-28/desempenho-cooperacao-juridica-internacional-lava-jato > . Acesso em: junho de 2017.

${ }^{28}$ BRASIL, 1998.

${ }^{29}$ EUR-LEX. Access to European Union law. Disponível em: < http://eur-lex.europa.eu/legal-content/PT/TXT/?uri=LEGISSUM\%3Al33108> . Acesso em: novembro de 2017.
} 
Apesar de recentemente positivado pelo Código de Processo Civil (conforme item 3.), constata-se ainda que o Auxílio Direto, ou Mutual Legal Assistance (MLA), já possui ampla conceituação e estudo pela doutrina brasileira. ${ }^{30}$

Delimitando o alcance do instituto, tem-se que

O auxílio direto em matéria penal, de acordo com seu regime jurídico no Brasil, constitui um instituto de direito internacional público e de direito processual penal, previsto em tratado internacional devidamente incorporado ao ordenamento jurídico interno, com status de lei ordinária, por meio do qual se estabelece o intercâmbio entre países acerca de documentos, provas, atos e medidas processuais constritivas patrimoniais, por intermédio de uma Autoridade Central, incumbida da promoção da pretensão de um País, no interesse de uma investigação criminal ou de um processo penal no exterior (ativo) ou no Brasil (passivo). O seu conteúdo, compreendido pelas medidas que constituem o seu objeto, trata da realização de atos de investigação criminal e processuais penais em outro país, desde que diversos da extradição, configurando uma medida incidental e acessória a um feito principal de natureza processual penal: a persecução penal em trâmite no País requerente, materializada em uma investigação criminal (fase pré-processual) ou em uma ação penal (fase processual). ${ }^{31}$

Depreende-se então que o Auxílio Direto, desde que previsto em acordos internacionais, revelador de reciprocidade entre as nações, se propõe a inserir no processo penal ou procedimento investigativo do país interessado todos os elementos passíveis de colheita que recebem guarida no ordenamento do requerente. Sendo assim, a persecução penal conta com um colaborador estrangeiro, funcionando como verdadeiro longa manus dos legitimados nacionais (Polícia Judiciária, Ministério Público Federal, Justiça Federal, dentre outros) para a investigação ou colheita de provas.

A diferença procedimental que existe entre a Carta Rogatória e o Auxílio Direto (quando houver reserva de jurisdição) se dá quanto à análise de mérito no conteúdo de tais institutos.

${ }^{30}$ MEDEIROS, Ana Rosa de Brito. The International Cooperation in Criminal Matters and The International Assets Recovery: Progress and Challenges to Brazil in order to Fight Against the Money Laundering. 2012. 100 f. Dissertação (Mestrado em ciências Jurídicas) - Universidade Federal da Paraíba, João Pessoa, 2012; TEÓFILO, Anna Mayra Araújo; BRAGA Rômulo Rhemo Palitot. Cooperação Penal Internacional nos crimes de Lavagem De Dinheiro. Disponível em: <www.publicadireito.com.br/artigos/?cod=571e646d4ea4d46a > Acesso em: junho de 2017; IBANEZ, Alline Moreno. A Cooperação Jurídica no Mercosul e Novo Código de Processo Civil. Universidade Federal do Rio Grande do Sul. Porto Alegre, 2016. Disponível em: < http://www.lume.ufrgs.br/ handle/10183/150928>. Acesso em: novembro de 2017.

${ }^{31}$ FORNAZARI JUNIOR, Milton. PF em Pauta: Cooperação jurídica internacional. Atribuições legais no auxílio direto. Disponível em: < https://jota.info/artigos/pf-em-pauta-cooperacao-juridica-internacional-17032016>. Acesso em: junho de 2017. 
Enquanto que na Carta Rogatória o Poder Judiciário do país colaborador se limita a verificar o preenchimento dos requisitos formais para a realização da diligência (juízo de delibação pelo STJ no caso de cooperação passiva), no Auxílio Direto há uma análise material do disposto na demanda do país requerente (decisão judicial - com conteúdo decisório - interna). ${ }^{32}$ É esta inclusive a prescrição do art. 28 do $\mathrm{CPC}$, regrando que "cabe auxílio direto quando a medida não decorrer diretamente de decisão de autoridade jurisdicional estrangeira a ser submetida a juízo de delibação no Brasil."

\section{Assim é exposta a funcionalidade do instituto}

O Auxílio Direto diz respeito, portanto, à remessa, integral, de determinado fato ao judiciário estrangeiro, de maneira que este proporcione não apenas uma decisão sobre o mesmo, como também que execute, ou não, o que ficou decidido. ${ }^{33}$

Ilustrando, eventual pedido de quebra de sigilo bancário, visando apurar suposto crime de lavagem de capitais, não será destinado ao judiciário brasileiro para apreciação e futura remessa ao país destinatário para simples homologação e cumprimento, mas encaminhado o pleito diretamente ao órgão jurídico internacional responsável pelos provimentos do país estrangeiro, para que este possa deferir ou não a mitigação ao referido direito constitucional à intimidade.

O mecanismo em apreço tem se revelado mais eficiente, já que "em virtude da natureza muitas vezes fluída da prova, a rapidez em sua obtenção é indispensável”34 ${ }^{\prime \prime}$ mister com a premissa de que o juízo que receber o pedido terá cognição plena sobre o feito, podendo delimitar com maior qualidade o objeto a ser apurado.

No entanto, surge uma problemática relativa à paridade de armas envolvendo o instituto em apreço. Apesar de o pedido de cooperação internacional ao Poder Judiciário estrangeiro, no caso do Auxílio Direto, prescindir da análise meritória pelo judiciário do país requerente, não há previsão nos diversos tratados internacionais para que a defesa técnica do investigado ou do réu figure como legitimado para o pleito ${ }^{35}$.

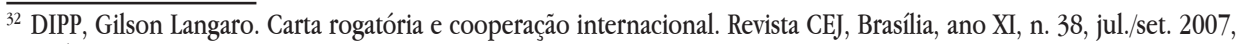
p. 40.

33 TEÓFILO, Anna Mayra Araújo; BRAGA Rômulo Rhemo Palitot. Cooperação Penal Internacional nos crimes de Lavagem De Dinheiro. Disponível em: <www.publicadireito.com.br/artigos/?cod=571e646d4ea4d46a > . Acesso em: junho de 2017.

${ }^{34}$ TOFFOLI, José Antônio Dias; Cestari, VIRGÍNIA Charpinel Junger. Mecanismos de Cooperação Jurídica Internacional No Brasil. Disponível em: <www.agu.gov.br/page/download/index/id/1070064> . Acesso em: junho de 2017.

${ }^{35}$ SANTOS, Laura Rodrigues dos. Cooperação Jurídica Internacional em Matéria Criminal: das Rogatórias ao Auxílio Direto, p. 14. Disponível em: < http://www.justica.gov.br/sua-protecao/cooperacao-internacional/cooperacao-juridica-internacional-em-materia-penal> . Acesso em: junho de 2017.
} 
Tal dissonância viola gravemente, em última instância, o direito à ampla defesa do acusado, já que a relação diplomática internacional teria seu uso limitado aos órgãos de persecução penal, não sendo viável que a defesa perquira elementos a embasarem eventual álibi de seu cliente.

O referido óbice encontra materialidade no Mutual Legal Assistance Treaty (MLAT) Brasil/EUA e no protocolo de São Luís, que veda aos particulares, leia-se, pessoas estranhas aos órgãos integrantes do Estado requerente, a solicitação em fase inquisitorial de assistência visando a obtenção de provas. ${ }^{36}$

\section{AUXÍLIO INTERNACIONAL NA DECRETAÇÃO DE MEDIDAS CAUTELARES EM CRIMES ENVOLVENDO A LAVAGEM DE CAPITAIS}

No processo penal, as medidas assecuratórias reais ${ }^{37}$ visam preservar certo patrimônio para que seja aproveitado em eventual efeito da condenação (art. 91 do Código Penal e art. $7^{\circ}$ da lei $n^{0} 9.613$ de 1998). Em se tratando de lavagem de capitais, o objetivo, além de assegurar futura perda de bens e valores, cuja origem é criminosa, visa romper com o iter criminis, evitando que as etapas envolvendo a reinserção dos valores no mercado financeiro sejam cumpridas.

Há previsão, no art. $4^{0}$ da lei no 9.618 de $1998^{38}$, do juiz decretar medidas cautelares reais sobre ativos em que há indícios suficientes de que são provenientes de atividade criminosa.

Apesar de constar apenas produto de crime no caput do dispositivo legal, seus parágrafos regulam a restrição de bens cuja origem é lícita, aptos a repararem o dano causado pela Lavagem de Capitais ou pelos crimes antecedentes perpetrados.

Em se tratando de ocultação ou dissimulação de bens, direitos ou valores provenientes, direta ou indiretamente, de infração penal, se faz ainda mais necessária a aplicação de medidas aptas a restringirem a movimentação de tais ativos. Isto porque a execução e o exaurimento da lavagem de dinheiro consistem numa dinâmica em que o produto oriundo de atividade delituosa não pode ficar à mercê

\footnotetext{
${ }^{36}$ SANTOS, Laura Rodrigues dos, op cit. p. 21-22.

${ }^{37}$ Apreensão; sequestro; especialização e registro de hipoteca legal; arresto.

${ }^{38} \mathrm{O}$ juiz, de ofício, a requerimento do Ministério Público ou mediante representação do delegado de polícia, ouvido o Ministério Público em 24 (vinte e quatro) horas, havendo indícios suficientes de infração penal, poderá decretar medidas assecuratórias de bens, direitos ou valores do investigado ou acusado, ou existentes em nome de interpostas pessoas, que sejam instrumento, produto ou proveito dos crimes previstos nesta Lei ou das infrações penais antecedentes.
} 
de autoridades e investigações, precisa ser transferido a terceiros, investido em atividades idôneas etc., visando assim ganhar caráter de licitude.

Assim, o periculum in mora, imprescindivel a autorizar qualquer medida cautelar, é ainda mais evidente em crimes envolvendo a lei $\mathrm{n}^{0} 9.613$ de 1998, já que o agente criminoso objetiva desde o início dilapidar ou ocultar seu patrimônio, sendo, a depender das operações já consumadas, cada vez mais difícil a localização de bens ou valores. ${ }^{39}$

Feito este introito, cabe tecer comentários acerca de acordos internacionais que visam dar efetividade aos instrumentos postos à disposição do judiciário brasileiro para que possíveis apreensões e restituições de bens e valores sejam garantidas ao final da ação penal.

Na Lei de Lavagem de Capitais, há previsão no sentido de que, havendo ou não tratado ou convenção internacional (desde que havendo reciprocidade), o juiz da causa determinará medidas cautelares reais que incidirão nos bens e valores cuja origem seja infracional ${ }^{40}$, ou que servirem de reparação futura quaisquer efeitos da condenação, possibilidade já exposta no presente estudo.

Notável que a previsão legal indica a cooperação passiva do Estado brasileiro. E é neste aspecto que a doutrina ${ }^{41}$ ainda se limita ao instituto da Carta Rogatória. Novamente, expõe-se que

[...] a autoridade jurisdicional brasileira pode colaborar com autoridade estrangeira competente, no sentido de determinar medidas assecuratórias sobre bens, direitos ou valores oriundos de crimes descritos no art. $1^{\circ}$ da Lei no 9.613/98 praticados no estrangeiro. Para tanto, impõe-se carta rogatória, a ser cumprida pela Seção Judiciária da Justiça Federal onde estiver o bem, após a concessão de exequatur pelo Superior Tribunal de Justiça [...]. ${ }^{42}$

Como já exposto, o prévio juízo de delibação pelo STJ já não cumpre com a celeridade necessária a assegurar barreiras na dinâmica da lavagem de capitais.

\footnotetext{
${ }^{39}$ LIMA, Renato Brasileiro de. Legislação Criminal Especial Comentada: volume único. 4. ed., rev., ampl. e atual. Salvador: JusPODVM, 2016, p. 401.

${ }^{40}$ Art. 80 da Lei no 8.613/98: O juiz determinará, na hipótese de existência de tratado ou convenção internacional e por solicitação de autoridade estrangeira competente, medidas assecuratórias sobre bens, direitos ou valores oriundos de crimes descritos no art. 1o praticados no estrangeiro. $\S 1^{\circ}$ Aplica-se o disposto neste artigo, independentemente de tratado ou convenção internacional, quando o governo do país da autoridade solicitante prometer reciprocidade ao Brasil.

${ }^{41}$ NUCCI, Guilherme de Souza. Leis penais e processuais penais comentadas. 8. ed. rev., atual. e ampl. vol. 2. Rio de Janeiro: Forense, 2014, p. 470.

${ }^{42}$ LIMA, Renato Brasileiro de. Legislação Criminal Especial Comentada: volume único. 4. ed., rev., ampl. e atual. Salvador: JusPODVM, 2016, p. 459-460.
} 
Assim, há que se compreender que a utilização de Auxílio Direito, instrumento inovador e que revela maior eficácia, é também possível quando da observância do referido art. $8^{\circ}$ da lei $n^{\circ} 9.613 / 1998$. A leitura do próprio enunciado abre tal caminho, haja vista que permite ao juiz nacional a análise meritória do feito, já que recebera o pedido diretamente da autoridade estrangeira competente.

Tratando das disposições da Convenção de Palermo de 2000

Há previsão da cooperação estrita entre os países, em conformidade com os ordenamentos jurídicos internos, devendo haver o reforço ou criação de canais de comunicação entre as Estados para o auxílio na investigação dos crimes previstos na Convenção. Para tanto, os países se comprometem a cooperar na produção de provas, cumprindo solicitações de bloqueios de bens, busca e apreensão ou outras medidas cautelares, prestações de informações, constatação sobre a veracidade de documentos, movimentações bancárias suspeitas, ou outras formas para facilitar a investigação e eventual condenação de envolvidos, respeitando-se sempre o direito interno. ${ }^{43}$

Verifica-se, então, que as autoridades brasileiras, conforme exemplo retro, possuem meios sofisticados para identificarem e bloquearem operações financeiras suspeitas, podendo a evasão de divisas ser interrompida e caracterizada a conduta delituosa.

Mas, no plano interno, que sistema o Brasil possui para fornecer dados necessários à recuperação de ativos oriundos de lavagem de capitais?

Baseado na lei no 9.613 de 1998, que também buscou instituir mecanismos de controle às movimentações financeiras suspeitas, o Banco Central editou normas visando a obtenção de dados para mapear e evitar a movimentação de valores oriundos de atividades ilícitas, como por exemplo as cartas circular $\mathrm{n}^{\circ} 3.461,3.542$ e 3.430, que consolidam as regras sobre os procedimentos a serem adotados na prevenção e combate às atividades relacionadas com os crimes previstos na lei $\mathrm{n}^{\mathrm{o}}$ 9.613 de 1998 e divulgam a relação de operações e situações que podem configurar indícios de ocorrência dos referidos delitos, passíveis de comunicação ao Conselho de Controle de Atividades Financeiras (COAF). ${ }^{44}$

\footnotetext{
${ }^{43}$ BAQUEIRO, Fernanda Ravazzano Lopes. Da Insuficiência Dos Mecanismos De Cooperação Jurídica Internacional No MERCOSUL Para Repressão Aos Crimes Transnacionais: Uma Proposta Para Criação Do Tribunal Penal Do MERCOSUL. Direito internacional II [Recurso eletrônico on-line] organização CONPEDI/UdelaR/Unisinos/ URI/UFSM /Univali/UPF/FURG; 1. Direito Estudo e ensino (Pós-graduação) Encontros Internacionais. 2. Direito internacional. I. Encontro Internacional do CONPEDI (5. 2016: Montevidéu, URU), p. 207-208.

${ }^{44}$ Banco Central do Brasil. Legislação e normas editadas pelo Banco Central. Disponível em: < https://www.bcb. gov.br/fis/supervisao/lavdinreg.asp > . Acesso em: julho de 2017.
} 
Também é prescrito no art. $3^{\circ}$, I e VI, da lei complementar n ${ }^{0} 105 / 2001$ que não constituiu violação ao dever de sigilo a troca de informações entre instituições financeiras, para fins cadastrais e a comunicação, às autoridades competentes, da prática de ilícitos penais ou administrativos, abrangendo o fornecimento de informações sobre operações que envolvam recursos provenientes de qualquer prática criminosa. ${ }^{45}$

Ou seja, não há dúvidas que o Brasil possui aparato legal para o rastreamento de ativos ilícitos, havendo dificuldades apenas no que toca à recuperação dos mesmos, haja vista que o caráter dinâmico da lavagem de capitais permite aos criminosos rápida ocultação do capital.

\section{PROCEDIMENTO PARA REQUISIÇÃO DE COOPERAÇÃO JURÍDICA INTERNACIONAL}

Conforme regram os incisos IV e VI do art. 12, Anexo I do decreto $\mathrm{n}^{\mathrm{O}}$ 9.150/2017 ${ }^{46}$, que trata da Estrutura Regimental do Ministério da Justiça, compete ao Departamento de Recuperação de Ativos e Cooperação Jurídica Internacional (DRCI) exercer a função de Autoridade Central, entidade responsável por dar andamento à requisições dos órgãos interessados, tanto no aspecto ativo quanto no aspecto passivo da cooperação. Tal órgão tem como objetivo central a recuperação de valores ligados à lavagem de dinheiro.

No Brasil, o Manual de Cooperação Jurídica internacional e Recuperação de Ativos $^{47}$ revela que o trâmite envolvendo a cooperação jurídica internacional ativa se inicia em âmbito administrativo.

Ao receber o pedido de diligências, o DRCI, após analisar o preenchimento dos requisitos de admissibilidade do Auxílio Direto ou da Carta Rogatória (previsão

45 BRASIL, 2001.

${ }^{46}$ Art. 12. Ao Departamento de Recuperação de Ativos e Cooperação Jurídica Internacional compete: [...] IV exercer a função de autoridade central, por meio da coordenação e da instrução de pedidos ativos e passivos de cooperação jurídica internacional nas áreas a que se refere o inciso III, por delegação do Ministro de Estado, exceto se houver designação específica que disponha de maneira diversa; [...] VI - negociar acordos de cooperação jurídica internacional nas áreas a que se refere o inciso III e aqueles relacionados com os demais temas de sua competência, além de exercer as funções de ponto de contato, enlace e similares nas redes de cooperação internacional e de recuperação de ativos.

${ }^{47}$ Secretaria Nacional de Justiça. Departamento de Recuperação de Ativos e Cooperação Jurídica Internacional. Manual de cooperação jurídica internacional e recuperação de ativos: cooperação em matéria penal / Secretaria Nacional de Justiça, Departamento de Recuperação de Ativos e Cooperação Jurídica Internacional (DRCI). 2. ed. Brasília: Ministério da Justiça, 2012, p. 80-81. 
em tratados internacionais no caso do Auxílio Direto e subsunção aos arts. 783 e seguintes no caso de Carta Rogatória), encaminhará o pleito à Autoridade Central do país requisitado (estando os documentos pertinentes devidamente traduzidos) ${ }^{48}$, que por sua vez, seguindo rito interno, remeterá o pedido ao órgão judiciário competente para processar, julgar e executar a diligência, momento em que o resultado da colaboração será devolvido pela mesma via.

Em segundo momento, não havendo tratados ou convenções internacionais entre os sujeitos ativo e passivo da relação, a colaboração dependerá de meios diplomáticos para efetivação, em que é verificada a reciprocidade para com o país solicitado. Neste aspecto, o DRCI, ao receber o pedido de autoridades, remeterá o pleito ao Ministério das Relações Exteriores brasileiro, que será responsável por encaminhar o feito à representação brasileira no exterior (consulado), que finalmente remeterá à entidade estrangeira responsável pelo trâmite interno.

Já a cooperação jurídica internacional passiva receberia o mesmo tratamento, porém, seguindo rito inverso.

Seria a Justiça Federal de primeira instância o órgão brasileiro responsável por processar e julgar os pedidos remetidos pelo $\mathrm{DRCI}^{49}$. Em se tratando de Auxílio Direto, tal órgão julgaria o mérito do feito. Tratando o pedido de Carta Rogatória, o trâmite dependeria do juízo de delibação do STJ (exequatur), situação em que o judiciário brasileiro apenas analisaria os requisitos formais, não possuindo cognição exauriente sobre o tema.

Por fim, quando o pedido de cooperação passiva não depender de provimento judicial, se limitando a decisões administrativas, ao receber a requisição, o DRCI poderá encaminhá-la à Coordenação Geral de Polícia Criminal Internacional do Departamento de Polícia Federal ou outro órgão com atribuições que não dependam de prévia manifestação do Poder Judiciário. ${ }^{50}$

\footnotetext{
${ }^{48}$ MEDEIROS, Ana Rosa de Brito. The International Cooperation in Criminal Matters and The International Assets Recovery: Progress and Challenges to Brazil in order to Fight Against the Money Laundering. 2012. 100f. Dissertação (Mestrado em ciências Jurídicas) - Universidade Federal da Paraíba, João Pessoa, 2012, p. 64.

${ }^{49}$ Art. 109, III da CRFB/88: Aos juízes federais compete processar e julgar as causas fundadas em tratado ou contrato da União com Estado estrangeiro ou organismo internacional.

${ }^{50}$ Secretaria Nacional de Justiça. Departamento de Recuperação de Ativos e Cooperação Jurídica Internacional. Manual de cooperação jurídica internacional e recuperação de ativos: cooperação em matéria penal / Secretaria Nacional de Justiça, Departamento de Recuperação de Ativos e Cooperação Jurídica Internacional (DRCI). 2. ed. Brasília: Ministério da Justiça, 2012, p. 82-84.
} 


\subsection{SOLICITAÇÃO DE DADOS BANCÁRIOS PARA APURAR FATOS ENVOLVENDO LAVAGEM DE CAPITAIS}

Conforme já exposto no presente estudo, a lavagem de dinheiro que adquire caráter internacional, além de revelar o grau de sofisticação de organizações criminosas, torna cada vez mais árdua a tarefa de localizar os bens oriundos de atividades ilícitas.

Sendo o auxílio estrangeiro o único meio de continuar a investigação e instrução de eventual ação penal envolvendo infratores à lei no 9.613 de 1998, é o próprio Ministério da Justiça brasileiro quem propicia à PF, MPF, JF ou demais interessados a maneira de requisitar a diligência mais pertinente quando o assunto é rastreamento de ativos.

É também no Manual de Cooperação Jurídica internacional e Recuperação de Ativos $^{51}$ que há dados a serem observados para que a cooperação ativa proceda de maneira eficaz.

Primeiramente, além dos requisitos formais (endereçamento e demonstração de existência de tratados firmados pelos envolvidos), o formulário de solicitação de documentos bancários deverá conter os fatos que permitirão à autoridade estrangeira tomar conhecimento de todo o contexto envolvendo a transação financeira.

Considerando a prestação de Auxílio Direto, a autoridade requerente deverá expor a subsunção dos fatos narrados aos crimes punidos pela lei pátria e também o preenchimento dos requisitos para quebra de sigilo bancário do agente criminoso.

Neste aspecto, regulando a mitigação do art. $5^{\circ}$, X da Constituição da República Federativa do Brasil (CRFB) de $1988^{52}$, dispôs a lei complementar $\mathrm{n}^{\mathrm{0}}$ 105/2001 acerca do sigilo das operações de instituições financeiras. E é em seu art. $4^{\mathrm{o}}, \mathrm{VIII}^{53}$ que está a autorização legal para quebra de sigilo bancário visando apurar lavagem de dinheiro ou ocultação de bens, direitos e valores. Ou seja, a autoridade estrangeira deverá pleitear à brasileira como se aqui estivesse peticionando, devendo atentarse as regras do Brasil relativas ao sigilo bancário ${ }^{54}$.

${ }^{51}$ Ibidem, p. 93-94.

${ }^{52}$ Art. $5^{\circ}$, X: são invioláveis a intimidade, a vida privada, a honra e a imagem das pessoas, assegurado o direito a indenização pelo dano material ou moral decorrente de sua violação,

${ }^{53}$ Art. $4^{\mathrm{O}}$, VIII da LC 105/01: A quebra de sigilo poderá ser decretada, quando necessária para apuração de ocorrência de qualquer ilícito, em qualquer fase do inquérito ou do processo judicial, e especialmente nos seguintes crimes: [...] lavagem de dinheiro ou ocultação de bens, direitos e valores.

${ }^{54}$ Art. 26, § 3o do CPC: na cooperação jurídica internacional não será admitida a prática de atos que contrariem ou que produzam resultados incompatíveis com as normas fundamentais que regem o Estado brasileiro. 
Por fim, deve o sujeito ativo descrever pormenorizadamente os pedidos e os objetivos da operação, sendo imprescindível para o bloqueio e a recuperação de ativos ilícitos constar o registro de movimentação financeira interna, para que a autoridade estrangeira possua dados suficientes a concluir as diligências solicitadas.

Discussão que surge no âmbito prático é quanto à prescindibilidade de manifestação judicial, seja do país requerente, seja do país requerido, acerca da decretação de quebra do sigilo bancário.

Esposando que os órgãos administrativos, leia-se, Policial Federal e Ministério Público Federal, têm legitimidade para afastar diretamente o sigilo bancário, mediante requisição direta às entidades financeiras, em atenção ao art. 17-B da lei $\mathrm{n}^{0} 9.613$ de $1998^{55}$

Com relação a inafastabilidade da jurisdição, o fato do sigilo bancário ser afastado pelo Ministério Público e autoridades policiais nos crimes de lavagem de dinheiro não implica violação de qualquer direito ou garantia individual, pois qualquer violação aos limites legalmente impostos às requisições do Parquet ou autoridade policial, ou a qualquer abuso verificado na utilização das informações bancárias recebidas, poderá e deverá ser sempre controlado pelo Poder Judiciário, mediante provocação do interessado, como dispõe o artigo $5^{\circ}$, inciso XXXV, da Constituição Federal. [...]. Em particular ao afastamento do sigilo bancário e fiscal, o contraditório e ampla defesa inegavelmente estão inseridos na regulamentação da Lei Complementar 105/2001, uma vez que o art. $4^{\circ} \S 2^{\circ}$ do Decreto $n^{0} 3.724 / 01$ estabelece que a Requisição de informações sobre Movimentação Financeira - RMF será precedida de intimação ao sujeito passivo para apresentação de informações sobre a movimentação financeira, termo em que se constará a motivação da expedição. ${ }^{56}$

Verifica-se, então, que ante a existência de direitos fundamentais em colisão, sigilo bancário e segurança individual/social ${ }^{17}$, esta materializada pelo poder punitivo estatal, faz-se necessária a ponderação no caso concreto ${ }^{58}$, ante as premissas da legislação exposta, para que haja a efetiva obtenção dos dados financeiros, sem que

\footnotetext{
${ }^{55}$ Art. 17-B. A autoridade policial e o Ministério Público terão acesso, exclusivamente, aos dados cadastrais do investigado que informam qualificação pessoal, filiação e endereço, independentemente de autorização judicial, mantidos pela Justiça Eleitoral, pelas empresas telefônicas, pelas instituições financeiras, pelos provedores de internet e pelas administradoras de cartão de crédito.

${ }^{56}$ BUONODONO, Talytha Ferrari. O crime de lavagem de dinheiro e o afastamento do sigilo bancário. Disponível em: <https://jus.com.br/artigos/28495/o-crime-de-lavagem-de-dinheiro-e-o-afastamento-do-sigilo-bancario $>$. Acesso em julho de 2017.

${ }^{57}$ Art. $5^{\circ}$, caput e art. $6^{\circ}$ caput, ambos da CRFB $/ 88$.

${ }^{58}$ STF: Segunda Turma. Ag. Reg. no Inquérito 3.922/Ceará. Relator: Min. Dias Toffoli. Julgado em 15 de dezembro de 2015.
} 
tais informações sejam amplamente divulgadas, ou seja, deve ser utilizada apenas para fins criminais.

\section{CONSIDERAÇÕES FINAIS}

Considerando o caráter transnacional de crimes envolvendo a lavagem de dinheiro, em que sistemas financeiros nacionais são maculados por setores em que a base econômica é oriunda de valores ilícitos, faz-se cada vez mais necessária a cooperação jurídica internacional para combate e recuperação de vultuosos montantes.

Isto porque a atuação isolada de um país, apesar do amplo amparo legislativo, não se mostra suficiente à colheita de elementos probatórios aptos ao oferecimento da ação penal e eventual condenação.

Necessária, então, uma rede de cooperação internacional para imediato atendimento aos pedidos de diligência aptos a elucidarem eventuais delitos, interromperem o iter criminis ou auxiliarem na recuperação de ativos ilícitos, ferramenta imprescindível para alcance do fim útil dos atos investigatórios.

Sendo assim, apesar de não ser novidade no ordenamento pátrio, os meios pelas quais a prestação bilateral é exercida estão cada vez mais aprofundados, buscando sempre a celeridade na prestação, sem que o caráter de Estado soberano do país requerido seja afetado.

Pelo exposto neste estudo, foi constatado que o Auxílio Direto é instrumento mais eficiente quando o assunto é interromper a cadeia que move a lavagem de capitais. Apenas com um contato direto dos órgãos de investigação com o Poder Judiciário do país requerido é possível haver cognição exauriente a ponto de se estipular a melhor estratégia no rastreamento e recuperação de ativos inidôneos.

\section{REFERÊNCIAS}

ANSELMO, Márcio Adriano. Lavagem de dinheiro e cooperação jurídica internacional. São Paulo: Saraiva, 2013.

BANCO CENTRAL DO BRASIL. Legislação e normas editadas pelo Banco Central. Disponível em:<https://www.bcb.gov.br/fis/supervisao/lavdinreg.asp > . Acesso em julho de 2017. 
BAQUEIRO. Fernanda Ravazzano Lopes. Da Insuficiência dos Mecanismos de Cooperação Jurídica Internacional no MERCOSUL para Repressão aos Crimes Transnacionais: uma Proposta para Criação do Tribunal Penal do MERCOSUL. Anais... CONPEDI, 2016.

BOBBIO, Norberto et al. Dicionário de política. 6. ed. Trad. Carmem Varrialle et al. Brasília: Ed. da UnB, 1994.

BULOS, Uadi Lammêgo. Curso de direito constitucional. 8. ed. rev. e atual. de acordo com a Emenda Constitucional n. 76/2013. São Paulo: Saraiva, 2014.

BUONODONO, Talytha Ferrari. O crime de lavagem de dinheiro e o afastamento do sigilo bancário. Disponível em: < https://jus.com.br/artigos/28495/0-crimede-lavagem-de-dinheiro-e-o-afastamento-do-sigilo-bancario $>$. Acesso em: julho de 2017.

CONSELHO DE CONTROLE DE ATIVIDADES FINANCEIRAS. Fases da Lavagem de Dinheiro. Disponível em: < http://www.coaf.fazenda.gov.br/links-externos/fases-da -lavagem-de-dinheiro > . Acesso em novembro 2016.

DAMIN, Leonardo. Da importância da cooperação jurídica internacional nos crimes de lavagem de dinheiro. Disponível em: < https://eodamin.jusbrasil.com. br/artigos/433383334/da-importancia-da-cooperacao-juridica-internacional-nos-crimes-de-lavagem-de-dinheiro > . Acesso em: junho 2017.

DEPARTAMENTO DE RECUPERAÇÃO DE ATIVOS E COOPERAÇÃO JURÍDICA INTERNACIONAL. Disponível em: < http://portal.mj.gov.br> . Acesso em maio de 2017.

DIPP, Gilson Langaro. Carta rogatória e cooperação internacional. Revista CEJ, Brasília, ano XI, n. 38, jul./set. 2007. 
DITTRICH, Lalisa Froeder. Cooperação Jurídica Internacional relacionada à Operação Lava Jato. Cooperação em Pauta - no 14/2016. Disponível em: $<$ http://www.justica. gov.br/sua-protecao/lavagem-de-dinheiro/institucional-2/publicacoes/cooperacao-em-pauta/cooperacao-em-pauta-n14>. Acesso em: junho de 2017.

GIACOMET, Isalino Antonio; SILVEIRA, Arnaldo José Alves. Desempenho da cooperação jurídica internacional nos três anos de "lava jato". Disponível em: <http:/www.conjur.com. br/2017-mar-28/desempenho-cooperacao-juridica-internacional-lava-jato > . Acesso em: junho de 2017.

IBANEZ, Alline Moreno. A Cooperação Jurídica no Mercosul e Novo Código de Processo Civil. Universidade Federal do Rio Grande do Sul. Porto Alegre, 2016. Disponível em: <http://www.lume.ufrgs.br/handle/10183/150928>. Acesso em: novembro de 2017.

LIMA, Renato Brasileiro de. Legislação Criminal Especial Comentada: volume único. 4. ed. rev. ampl. e atual. Salvador: JusPODVM, 2016.

MEDEIROS, Ana Rosa de Brito. The International Cooperation in Criminal Matters and The International Assets Recovery: Progress and Challenges to Brazil in order to Fight Against the Money Laundering. 2012. 100 f. Dissertação (Mestrado em ciências Jurídicas) - Universidade Federal da Paraíba, João Pessoa, 2012.

NUCCI, Guilherme de Souza. Leis penais e processuais penais comentadas. 8 . ed. rev., atual. e ampl. Rio de Janeiro: Forense, 2014. vol. 2.

SANTOS Laura Rodrigues dos. Cooperação Jurídica Internacional em Matéria Criminal: das Rogatórias ao Auxílio Direto. p. 14. Disponível em: < http://www. justica.gov.br/sua-protecao/cooperacao-internacional/cooperacao-juridica-internacional-em-materia-penal> . Acesso em: junho de 2017.

SIQUEIRA, Marcelo Gustavo Silva. A Jurisdição e a Cooperação Internacional no Projeto de Lei do Novo Código de Processo Civil (conforme aprovado no Senado). Revista Eletrônica de Direito Processual - REDP, v.8.

STRECK, Lenio Luiz. Comentários ao código de processo civil; coordenador executivo Alexandre Freire. São Paulo: Saraiva, 2016. 
TEÓFILO, Anna Mayra Araújo; BRAGA Rômulo Rhemo Palitot. Cooperação Penal Internacional nos crimes de Lavagem De Dinheiro. Disponível em: <www.publicadireito.com.br/artigos/?cod=571e646d4ea4d46a > . Acesso em: junho de 2017.

TOFFOLI, José Antônio Dias; Cestari, VIRGÍNIA Charpinel Junger. Mecanismos De Cooperação Jurídica Internacional No Brasil. Disponível em www.agu.gov.br/ page/download/index/id/1070064. Acesso em junho de 2017.

TORRES, Heleno. Direito tributário internacional: planejamento tributário e cooperação transnacionais. São Paulo: Revista dos Tribunais, 2001.

WERNER, Guilherme Cunha. O crime organizado transnacional e as redes criminosas: presença e influência nas relações internacionais contemporâneas. Tese (Doutorado). São Paulo. Universidade de São Paulo. Departamento de Ciências Políticas, 2009. Disponível em: < http://www.tribunapr.com.br/noticias/o-crime-organizado-na-visao-da-convencao-de-alermo/> . Acesso em: novembro de 2017.

SECRETARIA NACIONAL DE JUSTIÇA. Departamento de Recuperação de Ativos e Cooperação Jurídica Internacional (DRCI). Manual de cooperação jurídica internacional e recuperação de ativos: cooperação em matéria penal. 2. ed. Brasília: Ministério da Justiça, 2012.

TRANSPARENCY INTERNATIONAL. Corruption Perceptions Index 2016. Disponível em: <https://www.transparency.org/news/feature/corruption_perceptions_index_2016>.Acesso em: julho de 2017.

Recebido em: 23/08/2017

Aceito em: 21/03/2018 